\title{
New Concept of Digital Structuring Landscape Space of Mountain Territories Landscape Sphere
}

\author{
Valeriy Titovich Starozhilov \\ Pacific International Landscape Center, Far Eastern Federal University, Vladivostok, Russia \\ Email: starozhilov.vt@dvfu.ru
}

How to cite this paper: Starozhilov, V. T. (2018). New Concept of Digital Structuring Landscape Space of Mountain Territories Landscape Sphere. Journal of Geoscience and Environment Protection, 6, 114-121. https://doi.org/10.4236/gep.2018.612008

Received: November 21, 2018

Accepted: December 21, 2018

Published: December 24, 2018

Copyright $\odot 2018$ by author and Scientific Research Publishing Inc. This work is licensed under the Creative Commons Attribution International License (CC BY 4.0).

http://creativecommons.org/licenses/by/4.0/

\section{(c) (i) Open Access}

\begin{abstract}
For the first time, a new concept of digital structuring of landscape space of mountainous territories is considered. It is proposed to carry out structuring and classification of landscape systems, with the distribution of high-altitude landscape complexes. When finding the boundaries of these complexes, the high-altitude selection criterion prevailed, as well as quantitative and qualitative changes in their internal content. According to these criteria, it is possible to distinguish between plain, low-slope, low-mountain, dissected-middle-mountain, massive-medium-mountain, altitude-landscape complexes. Structuring and classification are presented for further study of structures as objects of industry indications and possibilities of using high-growing complexes as development areas.
\end{abstract}

\section{Keywords}

Concept, Structuring, Mountain, Classification, Low-Mountain, Mid-Mountain, High-Landscape, Complexes, Industry Indication, Development

\section{Introduction}

The development of mountainous areas of the landscape sphere, such as the Pacific landscape belt of Russia, with its Sikhote-Alinskaya, Low-Amurskaya, Priokhotskaya, Kolymskaya, Anadyrskaya, Chukotskaya, Koryakskaya, Kamchatskaya, Sakhalinskaya regions (structures) sets the task of landscape science not only digital mapping and the development of scientific classifications of landscape creators, but also the structuring of landscape spaces in terms of the possibilities of using digital materials in practice. For the first time it is proposed to structure and classify mountain territories with the distribution of high-altitude 
landscape complexes, with the study of vertical and horizontal differentiation, changes in their internal content. Previously, the question of the proposed structuring and classification of landscape areas with the distribution of high-altitude landscape complexes was not considered. Structuring and classification were carried out at various scales at the planetary, medium-scale and local levels. The article discusses structuring at a medium-scale level. When identifying medium-scale high-altitude landscape complexes, the high-altitude criterion and quantitative and qualitative changes in their internal content are dominant, taking into account the state of erosion-denudation lowland and mountain landscape systems formed under the influence of the Earth's real energy flows and first of all gravitational energy. According to these criteria, landscape territories are classified and distinguished as plain, low-slope, low-mountain, dissected-middle-mountain, massive-medium-mountain, altitude-landscape complexes. The structuring and classification offered to the reader are presented for further study of the structures as objects of the sectoral indication and the possibilities of using high-landscape complexes as development territories. This study was carried out for the first time and aimed at the practical implementation of the landscape approach for the development of the territory, which determines the relevance of the work performed.

At present, the Far East Federal University Pacific International Landscape Center continues to develop a conceptual methodology for digitized structuring of the practical implementation of the method and the possibility of using these materials in developing the territory of Pacific Russia. The Far East Federal University Pacific geographers have already prepared a basic landscape map of Primorsky Krai at a scale of 1:500,000, a landscape map of the Russian island at a scale of 1:25,000, a landscape classification of the Sakhalin region, and continue research in other regions of the Pacific landscape belt of Russia.

\section{Materials and Methods}

The materials of the results of scientific and practical research in the field of geological and geographical study and landscape mapping of large regional Primorsky, Sakhalin and other units of the Pacific landscape belt of Russia (Starozhilov, 2018b) are considered (Figure 1). The materials of correlation and interrelation of rather significant data samples were studied not only on relief, vegetation and soils, but also on bedrock and loose rocks, climate. Also analyzed were the thickness of loose accumulations, transit of detrital material, moisture, depth of cut, thickness of dismemberment, intensity of physical and chemical weathering, meso and microclimatic features. First of all: solar radiation and radiance, temperature, wind, humidity, precipitation, snow cover, depth of frost penetration, various natural and extreme phenomena. In addition, based on the presentation of the significance of all components and factors of the landscape, including the foundation as a material component and its dynamics factor, we examine the landscapes and drawing up vector-layered landscape maps and physical-geographical zoning to consider the root and loose foundation (Starozhilov, 


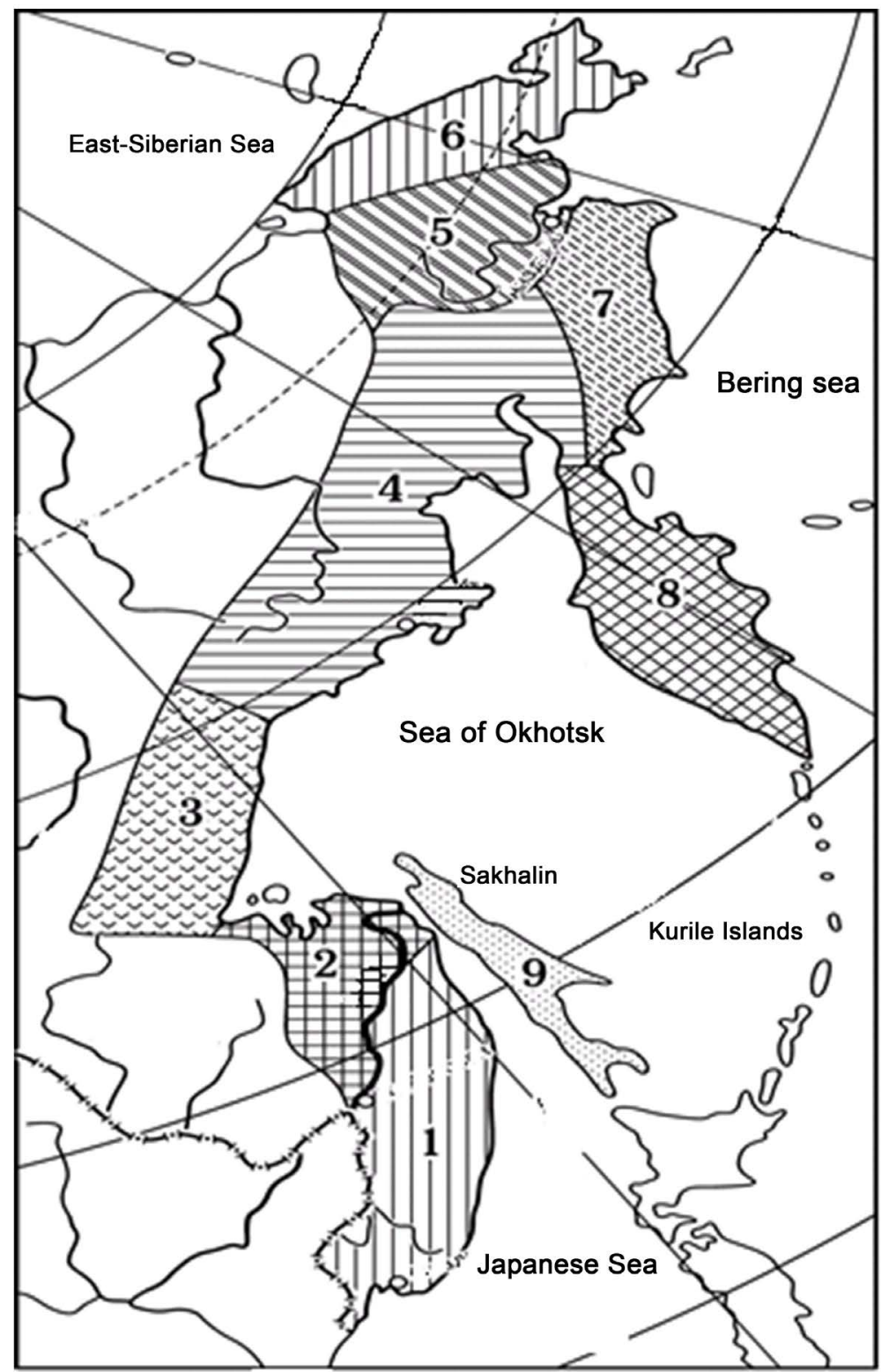

Belt areas: 1. Sikhote-Alinskaya, 2. Low-Amurskaya, 3. Priokhotskaya, 4. Kolymskaya, 5. Anadyrskaya, 6. Chukotskaya, 7. Koryakskaya, 8. Kamchatskaya, 9. Sakhalinskaya

Figure 1. Pacific landscape belt of Russia.

\section{1, 2018a).}

The article discusses the materials of the results obtained on the basis of the author's field (more than 30 field seasons of the author) and production on the practical implementation of the landscape method in various areas of environmental management: in the field of tourism and recreation, urban planning, organization of agricultural enterprises to create a production base in mountain taiga landscapes, forest management, planning and design of environmental management, etc. (Starozhilov, 2009b; Starozhilov et al., 2012; Starozhilov, 2018c).

We used the results of mapping individual regions of the Pacific landscape 
belt, for example, landscape classification, basic landscape map of Primorsky Krai M 1:500,000 and legend to it, developed at a scale of 1:500,000 landscape classification of the Sakhalin region (Starozhilov, 2016), ongoing landscape studies in other territories Pacific Russia; peculiarities of the formation of the foundation of landscapes of the Pacific landscape belt based on the author's concept of his accretionary geodynamic evolution, based on the study of the petrographic composition and structural-tectonic position of sedimentary and other lithocomplexes (Starozhilov, 2004, 2009c). The features of the structure and organization of landscapes, their location over the territory, taking into account the spatial-horizontal and altitudinal differentiation are taken into account (Starozhilov \& Zonov, 2009).

When identifying and classifying high-altitude landscape complexes, materials from the previously considered component, morphological, areal, and other landscape indications were used, which often serves as the basis for choosing the main direction or even a business strategy (Starozhilov, 2009d, 2017). The results of the previously developed concept of the poly-scale landscape indication were also used, the results of approbation of the method of landscape nodal development structures were used when planning the application of methods for searching mineral, phosphoric, apatite and other types of raw materials.

The above mentioned only part of the materials used, all the materials in the article reflect just not possible. They previously addressed specific issues in the performance of tasks in different sections of landscape science. Their general analysis as a basis for the concept of high-altitude landscape complexes and their classification has not previously been conducted. In this regard, all of them, including the author's field ( 30 field seasons), we used as the basis for solving the problem of structuring and classifying high-altitude landscape complexes.

In research methods are used: the method of conjugate analysis of intercomponent and interlandscape connections of landscape components (basement, relief, climate, water, vegetation, soil); the method of typological mapping in the classification system developed by us: tract, terrain, species, genus, subclass, landscape class; the concept (methodology) of the vector stratified landscape zoning and the study of the hierarchical structure and internal geographic content of the taxons of such zoning within the framework of mountain landscape science; vector techniques for GIS and vector-layered landscape mapping;

\section{Results}

In general, based on the analysis, synthesis and evaluation of significant field and theoretical material, the fundamental result of these studies has been established, namely, to implement the concept of structuring high-altitude landscape structures as the natural basis for conducting areas harmonized with nature, the development of sectoral areas is primarily digitized layered morphological landscape basis (for example, for Primorye, this is a vector-layered medium-scale landscape map of Primorsky Krai), to based on the digital level gives knowledge 
of the structure of the geographical space involved in the development of landscape structures. Such results, as shown by the author's studies on the example of mining and industrial systems (mining industry of Primorsky Krai) and studies on the practical implementation of the landscape approach in various industries, allow us to analyze the areas under digitalization from digitized landscape sections.

As a result of studies of landscapes of the Pacific landscape belt of Russia, using vector-layered digital landscape maps of various scales, it was found that in mountain and transitional structures with them, according to the altitude criterion and internal landscape content taking into account the state of erosion-denudation flat and mountain landscape systems that are emerging under the influence of the material and energy flows of the Earth and first of all gravitational energy (Starozhilov, 2009a), using the example of the Primorsky Territory, high-altitude landscape complexes. They are different and are divided into flat, low-slope, low-mountain, dissected, middle-mountainous, massive-medium-mountainous, alpine altitude-landscape complexes.

The plain high-landscape complex within the boundaries is clearly reflected in the morphological landscape maps and occupies the landscape plain space, for example, in the Primorsky Territory, occupies the landscape plain space of the Ussuri-Khanka landscape province (Starozhilov, 2018d). It includes the flat territory of the Far Eastern flat class of landscapes with its characteristic combination of forest-steppe plain and valley-river subclass and plain erosion-accumulative and valley-river and seaside-plain birth. Common for the complex - the predominance of erosion or abrasion (for coastal areas) origin of loose (detrital) material, mainly its water transit and accumulation in the conditions of small slopes of surfaces, chemical weathering of basement rocks, intensive manifestation of suffusion, lateral soil erosion, water and wind soil erosion, accumulation of loamy and clayey strata in low spaces.

Low-altitude high-landscape complex. It has an absolute mark of less than 300 $\mathrm{m}$. It is most common in the territories framing the Ussuri-Khanka plain.

In the east of the plain, in the transition zone to the West-Sikhote-Alin low-mountain region, these are separate elevations or ridges, dissected by accumulative valleys. To the south, their number increases, and in the west of the plain they are more widely distributed. The characteristic feature of the mountains is the different steepness of the upper $\left(15^{\circ}-20^{\circ}\right)$ and lower $\left(3^{\circ}-4^{\circ}\right)$ parts of the slopes, their concave, less often straight, profile of the slopes and small steepness, lack of rocky outcrops of bedrock.

It is characterized by a complex differentiation of plant and soil groups.

In general, the low-peak complex of landscapes is an area of delayed denudation and active alluvial and slope accumulation during material mobilization in the zone of destruction of the primary basement. Episodic occurrence of landslide, temperature, cryogenic and hygrogenic creep of slope accumulations.

Low-altitude landscape complex. It is widespread on the western macroslope 
of Sikhote-Alin, the East Manchurian Highlands and the narrow coastal strip of the Japanese Sea Macro slope.

These are mountains with absolute elevations of $300-800 \mathrm{~m}$ and relative elevations of up to $200-250 \mathrm{~m}$. They are characterized by straight, less often convex, slopes covered with a thick layer of gravelly loam, whose thickness at the foot of the mountains usually increases. Exposures are rare. This is usually either denudation outcrops and ridges, composed of weathering-resistant rocks on tops and slopes, or erosion (abrasion) precipices at the foot of the mountains.

In general, the low-altitude mountain-landscape complex is characterized by the complex differentiation of plant and soil groups. In Primorye, deciduous forests dominate among plant forests, and brown-forest forests dominate in soil. With delayed lateral removal of fine earth in the process of suffusion and lateral soil erosion, the predominant hot-dip and hygro-cry transit of slope deposits, with a noticeable enrichment of the upper layers of the section with coarse-graded material while preserving their predominantly loamy composition. The phenomena of intermediate slope accumulation at excesses and at the foot of the slope are widespread. The territories belong to sites with delayed denudation and active alluvial and slope accumulation.

The dismembered middle-mountainous high-landscape complex is developed in a territory with a deep dismemberment of the initially uniform arrays into a large number of narrow winding ridges and isolated peaks with deeply dissected slopes. It has an absolute elevation of more than $800 \mathrm{~m}$. These are areas with sharply defined watershed ridges, very steep straight or sloping slopes in the upper part, to which mobile scree, often covering slopes from bottom to top, are confined on the Japanese sea macro slope. Cedar-broadleaf and spruce-fir forests predominate among plant groups. On the slopes covered with woody vegetation, gravelly and gravelly-dresvenny loams are developed, which serve as the mineral basis of the prevailing brown and yellow-brown soils. Up the slope, there is usually an increase in the amount of coarse clastic material, its enrichment in the upper part of the slope accumulations, and the size of the clastic material increases. In general, the complex belongs to the field of active denudation, but the processes of alluvial transit and intermediate accumulation also play a significant role.

A massive middle-height high-landscape complex is characterized by the predominance of the most elevated dome-shaped massifs and linearly elongated mountain ranges, usually controlled by outcrops of the most resistant to weathering rocks. It has absolute marks of more than $800 \mathrm{~m}$. Tops of rounded outlines and flattened wide watersheds are widespread. Located in the central Sikhote-Alin, on the watersheds of Bikin, Bolshoy Ussurki and Ussuri. On the Japanese sea macro slope-in the basins of the Samarga, Maksimovka, Kema, Serebryanka, Kievka rivers. These are areas of taiga groupings of coniferous forests. The upper limit of the forest is formed by sub-hollow spruce forests, characterized by the powerful development of grass cover and shrub layer. The predominant soils are mountain taiga brown illuvial-humus, formed in conditions of 
rapid water exchange. Vegetation is formed on the blocky-dresveno-gravelly weathering crust with a relatively high content of loam in the section. In general, these are areas of active denudation and local accumulation.

The golets-based high-landscape complex is developed on the golets, under-mountain-mountain, stony placers, scree, kurums and stony streams, confined to the ridges of the watersheds, tops and slopes of the mountains, are not widely developed. In most cases, these are the most elevated parts of the mountains, rounded peaks and terraced slopes. On the northern Sikhote-Alin, landscapes of this high-landscape complex are often noted from 700 to $900 \mathrm{~m}$ marks, on the southern-they rarely fall below $1100 \mathrm{~m}$. Most often they are developed on the watersheds of the Bikin and Bolshaya Ussurka rivers, in the headwaters. Ussuri and watersheds of the Japan Sea of Macro Slope.

\section{Conclusion}

Subject to the use of vector-layer mapping, the study of landscapes using component, morphological, areal, poly-scale vector-layer display in the classification units of landscapes (landscape, type, genus, subclass, class, type, district, province, region, belt), will allow cartographically using modern digital computer technologies to move on to the consideration of scientific and practical tools harmonized with nature planning and forecasting economic, social, environmental and other systems. Structuring will be conducive to solving the problems of optimizing the natural environment of the regions.

\section{Conflicts of Interest}

The author declares no conflicts of interest regarding the publication of this paper.

\section{References}

Starozhilov, V. T. (2004). Geodynamic Evolution of Transition Zones of Northeast Asia to the Pacific Plate. In Hydrometeorological and Geographical Research in the Far East: Materials of the 5th anniversary Scientific Conference "Towards the World Water and Meteorology Days”(pp. 85-88). Vladivostok: Publishing House Dal'nevost.

Starozhilov, V. T. (2009a). Denudation Processes in Landscapes and Geoecological Prerequisites for Technological Change: Monograph (p. 137). Vladivostok: Publishing House Dal'nevost.

Starozhilov, V. T. (2009b). Ensuring the Environmental Safety of Environmental Risk Sources at Tin-Ore Enterprises in the South of the Far East. Ecology and Life Safety, № $4,81-88$

Starozhilov, V. T. (2009c). Geoecology of the Mineral Resource Use of Landscapes in the South of the Far East. Vladivostok: Ministry of Education and Science of the Russian Federation, Federal Agency for Education, Far Eastern Branch of the Russian Academy of Sciences, Institute of Mining, Far Eastern Federal University.

Starozhilov, V. T. (2009d). The Processes of Mechanical Soil Degradation in Landscapes of Primorye (p. 88). Vladivostok: Publishing House Dal'nevost.

Starozhilov, V. T. (2011). General Landscape Science and the Use of a Landscape Ap- 
proach in Environmental Monitoring of Environmental Management: A Course of Lectures (p. 286). Vladivostok: Publishing House Dal'nevost.

Starozhilov, V. T., Derbentseva, A. M., Nazarkina, A. V., Mayorova, L. P., Matveenko, T. I., Semal, V. A., \& Morozova, G. Yu. (2012). Soils and Man-Made Surface Formations in Urban Landscapes: Vladivostok: Ministry of Education and Science of the Russian Federation, Far Eastern Federal University, University of Biology and Soil Science, Pacific State University.

Starozhilov, V. T. (2016). Landscape Geosystems of the Sakhalin Link of the Marginal Continental Landscape Belt of Pacific Russia. Problems of Regional Ecology, № 5, 53-57.

Starozhilov, V. T. (2017). The Concept of Areal Landscape Indication in the Policy of the Pacific International Landscape Center SHEN FEFU (pp. 37-39). Materials Coll. Scientificst. on the Basis of the Intern. Scientific-Practical Conf. SPb.: KultInform Press Publishing House.

Starozhilov, V. T. (2018a). Landscape Geography of the South Pacific Landscape Belt of Russia. Regional Component Specificity and Spatial Analysis of Geosystems on the Example of Primorsky Krai: Textbook (p. 316). Vladivostok: Publishing House Dal'nevost.

Starozhilov, V. T. (2018b). Landscape Zoning of the South of the Pacific Landscape Belt of Russia: Textbook (p. 350). Vladivostok: Publishing House Dal'nevost. federal University.

Starozhilov, V. T. (2018c). Nature Management: Practical Landscape Geography: Textbook (p. 276). Vladivostok: Publishing House Dal'nevost.

Starozhilov, V. T. (2018d). Pacific Marginal Continental Landscape Belt as a Geographical unit of Pacific Russia and Environmental Management Issues. Problems of Regional Ecology, № 5, 1-10.

Starozhilov, V. T., \& Zonov, Yu. B. (2009). Study of Landscapes of Primorsky Krai for the Purposes of Nature Management. Geography and Natural Resources, № 2, 94-100. 